\title{
Quantifying the Size Effect of Rock Mass Strength
}

\author{
P.A. Cundall Itasca Consulting Group, USA
}

M.E. Pierce Itasca Consulting Group, USA

D. Mas Ivars Itasca Geomekanik, Sweden

\begin{abstract}
A long-standing problem in rock mechanics is the estimation of rock mass strength. The term "rock mass" denotes a large volume of fractured rock in which yield of intact material and discontinuities (joints) must both occur for overall failure to take place. The difficulty in characterising a rock mass arises from the impossibility of testing directly (to failure) a large extent of rock. Because the proportion and configuration of the discontinuities (relative to the proportion of intact rock) determine the strength of the composite material, there is a pronounced size effect, such that large volumes appear weaker than small volumes. It is therefore important to consider the size effect in the design of large structures in rock.
\end{abstract}

Recently, a numerical approach, called synthetic rock mass (SRM), has been developed and applied in several projects. The SRM is a bonded-particle assembly representing brittle rock that contains multiple joints, each consisting of a planar array of bonds that obey a special model, the smooth joint model (SJM). The SJM allows slip and cracking at particle contacts, while respecting the given joint orientation rather than local contact orientations. Overall failure of an SRM element depends on both fracture of intact material (bond breaks) and yield of joint segments.

Results are presented from a series of numerical experiments on $3 D$ elements of various sizes. For the first time, we are able to quantify the variation of rock mass strength as a function of size. The results are discussed in relation to empirical methods commonly used in design.

\section{Introduction}

A rock mass consists of a large volume of rock that contains discontinuities (for example, joints and existing fractures). In order for overall failure to take place, fracture of intact material and failure on discontinuities must occur. The so-called rock bridges must break. Therefore, stability predictions of engineered rock structures must take account of the ensemble strength, but it is difficult to characterise an entire rock mass because of the impossibility of strength-testing a large extent of rock directly. Small-scale testing of rock cannot be applied at the field scale because of the well-known size effect whereby large volumes appear weaker than small volumes. Empirical methods of estimating rock mass strength do not often account for the size effect, which implies that the design of large structures in rock may be non-conservative. Here, we attempt to quantify the size effect in rock masses by synthesising the ensemble behaviour from the known behaviours of the components (joints and intact rock), which may be tested at small scale. This numerical scheme is known as the synthetic rock mass (SRM). It is worth recording the words of Brady and Brown (2004) when discussing scale effects:

"These considerations suggest that the specification of the mechanical properties of a rock mass is not a simple matter. In particular, the unlikely possibility of testing jointed rock specimens, at scales sufficient to represent the equivalent continuum satisfactorily, indicates that it is necessary to postulate and verify methods of synthesising rock mass properties from those of the constituent elements."

Here, we attempt to estimate the size effect for selected SRMs in order to illustrate how an apparently unmeasurable quantity may be derived in a systematic way from known quantities. 


\section{Postulated mechanisms for size effect}

There seem to be two scales at which mechanisms of size effects are discussed in the literature.

First, there is the existence of randomly distributed flaws in supposedly intact blocks of rock. Thus, Goodman (1980) summarises the effect of size on strength by citing studies on relatively small blocks of rock that do not contain systematic jointing. For example, the tests of Bieniawski and Van Heerden (1975) indicate that the unconfined compressive strength of iron ore, quartz diorite and coal decreases with size, reaching constant values around $1.5 \mathrm{~m}$ edge length. The explanation is that larger samples are likely to contain more flaws in "critical locations" (Goodman, 1980). Bažant and Chen (1997) also consider relatively small specimen sizes, and mention three basic theories of scaling that may be responsible for the observed size effects. One of these (the Weibull statistical theory of random strength: Weibull, 1939) also embodies the notion that more flaws lead to lower strength, but it does not seem appropriate for jointed rock in compression because "the structure fails if one element of the material attains the strength limit" (Bažant and Chen, 1997). On the contrary, rock typically embodies considerable redundancy and sliding cracks, which do not conform to the weakest link concept of failure. The other theories cited by Bažant and Chen (1997) involve crack "fractality" and the fracture energy released by large cracks. The latter effect is characterised by results derived from linear elastic fracture mechanics (LEFM), in which the strength of self-similar blocks (containing one tension crack) is proportional to $D^{-1 / 2}$, where $D$ is the block size. Again, the conceptual model does not correspond closely with the geometry and yield mechanisms of jointed rock.

The second scale at which mechanisms are discussed is when a volume of rock contains a number of existing discontinuities related to systematic jointing patterns rather than a random distribution of small flaws. This conceptual picture of a rock mass is illustrated in Figure 1, and is discussed in most textbooks on rock mechanics. The implied size-effect mechanism is that larger volumes contain more blocks, which provide greater freedom to develop failure mechanisms. A related argument is that smaller volumes of rock must involve intact rock failure, thus increasing the overall strength, while larger volumes are more likely to contain through-going pathways comprised of existing joints, which supply a weakening effect.

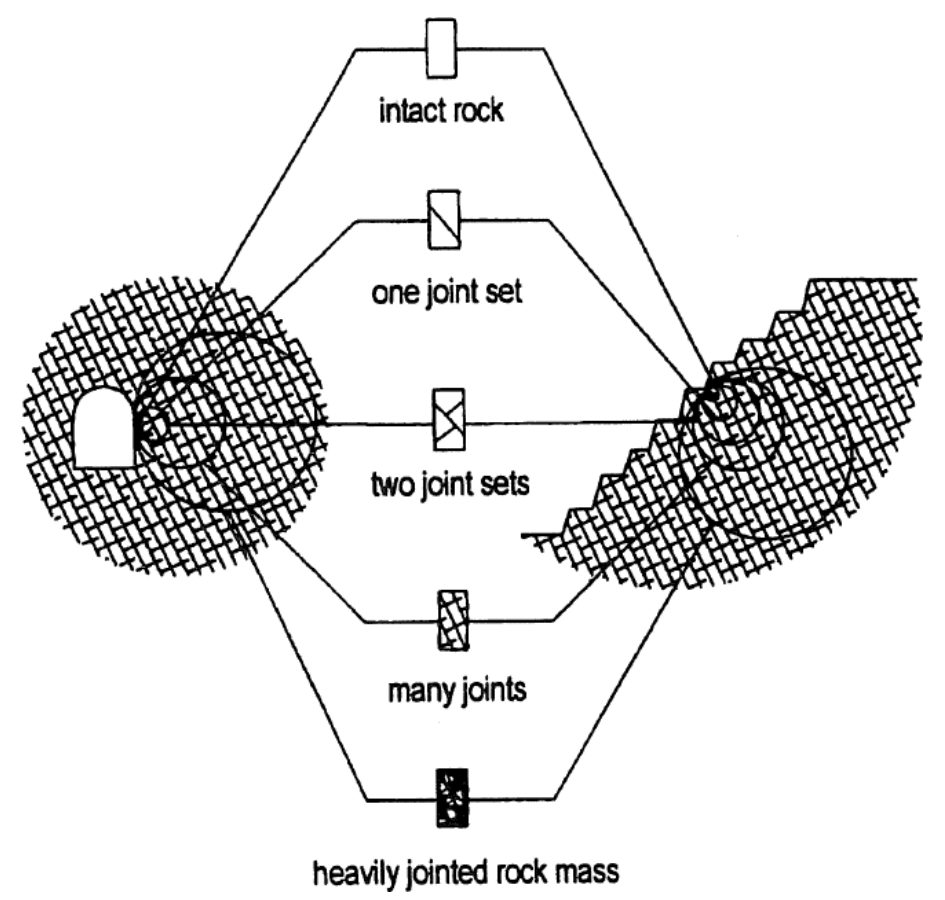

Figure 1 Concept of relative scale presented by Hoek and Brown (1997)

In this paper, we focus on the type of size effect that is related to the second scale - that is, the weakening effect of known (and mapped) jointing patterns. The effect of unmapped flaws in small blocks of rock (first scale) is taken into account by calibrating the "intact" strength of rock in our model to the strength associated with the mean size of blocks present in our numerical samples (see Section 5). 


\section{Previous work}

As noted by Schultz (1996) and others, one of the prerequisites for estimating the strength and deformation properties for a rock mass is to compare the scale of the problem (e.g. excavation size or sample size) to the scale of the fracture network (e.g. block size or fracture spacing). As the relative scale increases (i.e. as the sample size gets larger relative to the block size), the strength, modulus and spatial variability in these properties decrease. A review of laboratory and field studies of scale effects presented by Cunha (1990) suggests that the rate of decrease diminishes significantly above a certain scale, which is referred to as the representative elementary volume (REV).

When the relative scale reaches that of the REV, a rock mass often is considered treatable as a continuous material. As most empirical strength criteria for rock aim to predict the strength of the rock at this large relative scale (i.e. at or above the REV, where it may be considered continuous), some guidelines have been presented to assist the engineer in establishing this limit. Based on in situ plate-bearing tests on rock mass surfaces, Rocha (1974) suggested that the REV would be several times greater than the mean joint spacing. Schultz (1996) offers somewhat more quantitative guidance, suggesting that the rock mass may be considered a continuum when the problem scale exceeds the block size or fracture spacing by a factor of 5-10. Hoek and Brown (1997) simply state that in order to apply their empirical strength criterion, the slope or underground excavation should be "large and the block size small in comparison", resulting in the appearance of a "heavily jointed" rock mass, as illustrated in Figure 1.

Although Hoek and Brown (1997) seem to suggest that their approach offers an estimate of strength for rock masses at a scale at or above the REV, Mostyn and Douglas (2000) suggest that scale effects can be accounted for by interpreting the geologic strength index (GSI) at the scale of interest. This requires the user to judge both the structure (as defined by blockiness and degree of interlocking) and the surface conditions (as defined by surface quality) at the scale of interest. Cai et al. (2004) took this idea a step further, proposing a more quantitative means to account for structure and surface conditions within the GSI system (Figure 2). In their approach, the vertical axis of the GSI chart (representing structure) is replaced by block volume (in $\mathrm{cm}^{3}$ ), and the horizontal axis (representing surface conditions) is replaced by a joint condition factor (Jc) (see Cai et al., 2004 for a detailed description of Jc). This would seem to suggest that GSI is independent of the problem scale, but Kaiser (pers. comm., 2008) points out that the block volumes suggested by Cai et al. (2004) should be interpreted relative to the scale of a tunnel. Using the approach of Cai et al. (2004) and assuming a tunnel diameter of $5 \mathrm{~m}$, estimates of GSI and rock mass strength were derived as a function of joint condition factor and the relative scale of the problem (expressed as the number of blocks across the scale of interest). As shown in Figure 3, their approach would suggest that the REV (in terms of rock mass strength) may be approximately 20-30 times the block size, which is larger than the value of 5-10 that has been suggested by others.

While the approach suggested by Cai et al. offers an appealing means to derive GSI via more quantitative measures and to account for scale effects, it still requires estimation of block size relative to the problem scale, which can be a challenging task in rock masses with non-persistent joints. Kim et al. (2007) suggested that $U D E C$ (Itasca, 2004a) and 3DEC (Itasca, 2004b) could be used to derive such estimates from knowledge of the joint orientation, spacing and persistence. They were able to show that the block size distribution is sensitive to joint persistence and that both the block size and degree of interlocking increase as the joint persistence decreases (Figure 4). This was offered as support for the use of block size as a metric for degree of interlocking in the GSI system proposed by Cai et al. (2004). While such approaches may be useful for estimating block size distribution, they must be used with care in the estimation of rock mass strength in rock masses with non-persistent joints. As pointed out by Kim et al. (2007), the incomplete joints are (by default) deleted from the interior of blocks in $U D E C$ and $3 D E C$, as shown in Figure 4. If the expected rock mass failure mechanism involves block breakage (which would be particularly relevant at small relative scales), the presence of incomplete joints inside of large blocks (and, hence, the block strength) could have a significant contribution to rock mass strength and should not be eliminated. 


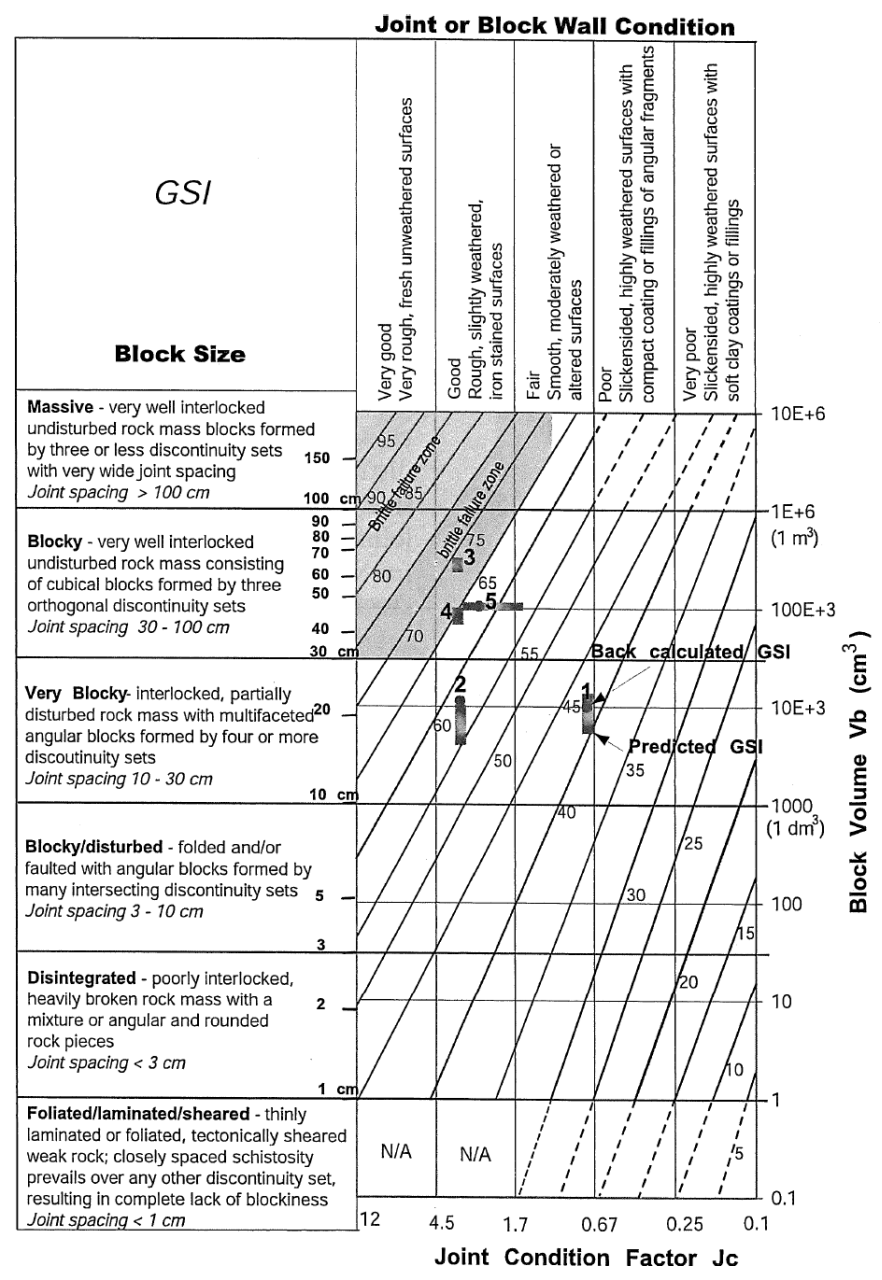

Figure 2 Quantification of the GSI System (Cai et al., 2004)

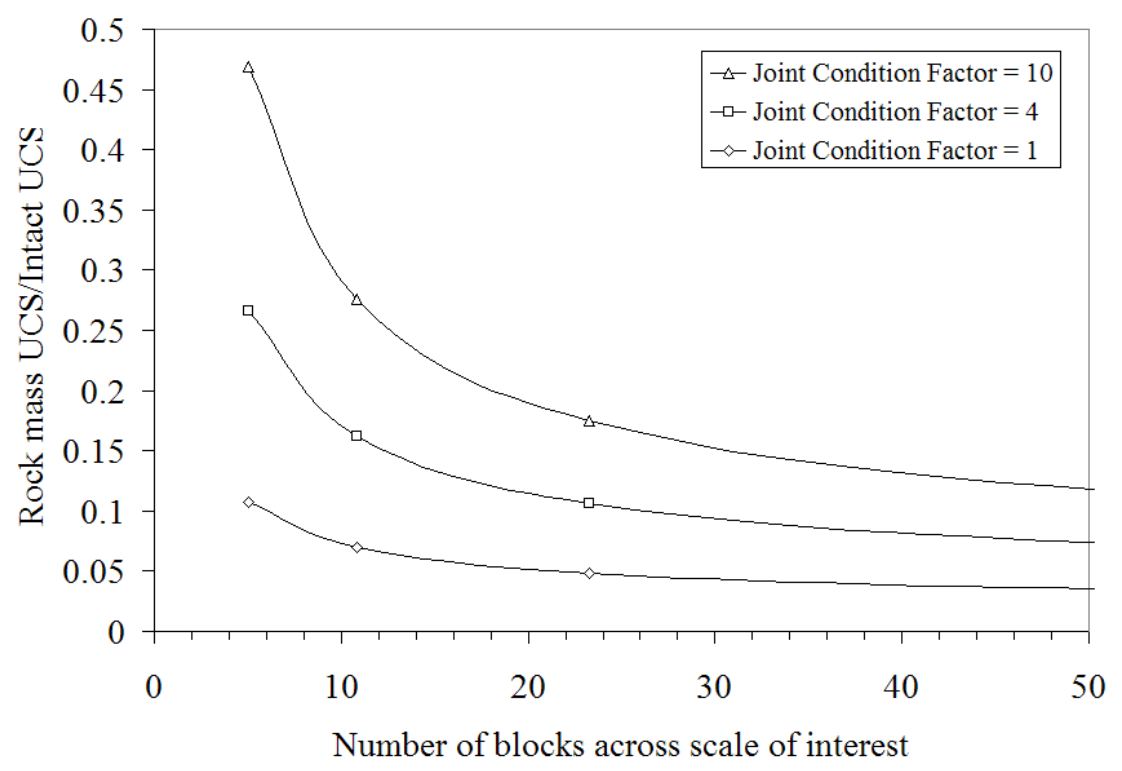

Figure 3 Rock mass strength as a function of relative scale as inferred from GSI approach of Cai et al. (2004), assuming a tunnel diameter of $5 \mathrm{~m}$ 

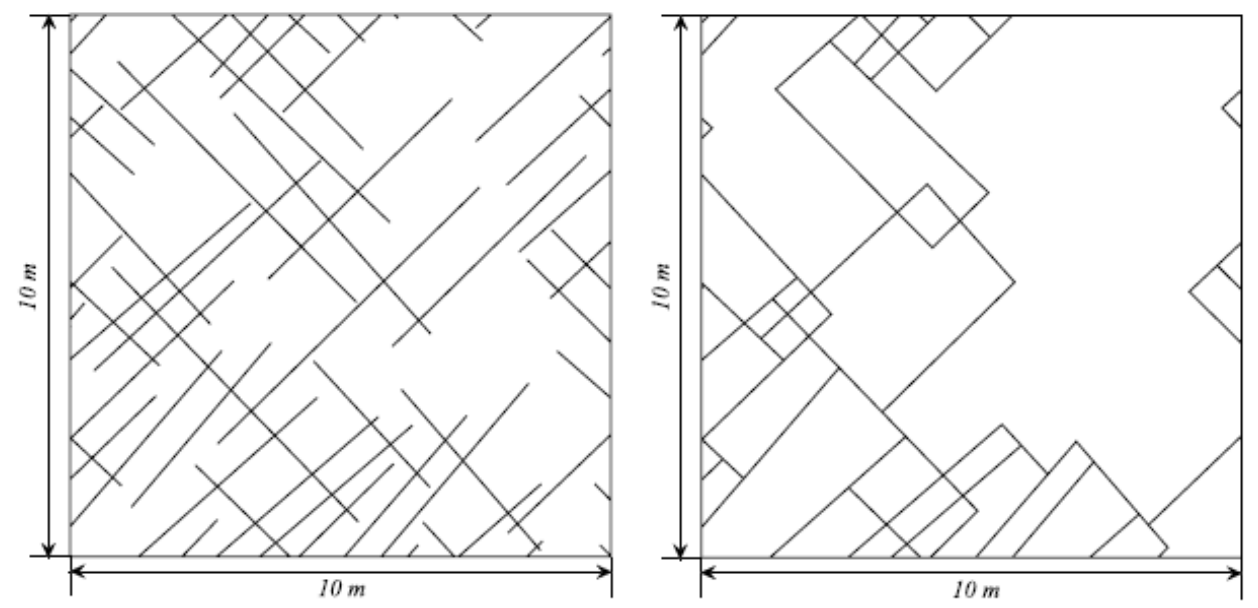

Figure 4 Estimation of block size in UDEC by Kim et al. (2007). Note impact of removing incomplete joints on block condition as well as the high degree of interlocking within larger blocks

This paper describes how PFC3D (Itasca, 2007) has been used to generate similar numerical representations of jointed rock masses in a scheme termed SRM, in order to study the effects of joint network geometry and scale on block size and rock mass strength. Unlike previous approaches, the SRM methodology allows for consideration of a complex non-persistent joint network as well as block breakage that includes the impact of incomplete joints on block strength. The technique has been applied to the analysis of block size distribution and rock mass strength as a function of joint network and problem scale. Similar approaches to SRM were made in two dimensions by Wang et al. (2003) and Park et al. (2004), but their representation of joint segments was compromised by the "bumpy" nature of the underlying particle model. The development of the smooth joint model (SJM, described in Section 4) has improved the physics of joint mechanics greatly and has allowed many more joint segments. Further, the simulations reported here are in three dimensions.

\section{Synthetic rock mass}

An SRM is a 3D representation of a jointed rock mass. It uses PFC3D to represent the intact rock as an assembly of bonded particles and an embedded discrete fracture network (DFN) to represent the joints as disc-shaped flaws. The intact rock is generated in PFC $3 D$ using the procedures described by Potyondy and Cundall (2004), and rock properties derived from standard laboratory testing. The DFN is generated using a random-disk modelling approach (ICSAS, 2006) and measures of joint geometry (orientation, density and size) derived from field mapping and core logging. The properties of the component joints are derived using standard laboratory or empirical methods. The joints are represented in the bonded-particle assembly with an SJM applied to particle contacts intersected by each joint (Mas Ivars et al., 2008b). The SJM ensures slip and opening in the direction of the joint, independently of the local directions of the contacts - see Figure 5 for an example of sliding on a single plane. Once an SRM is constructed, it may be subject to any stress or strain path and carried through to complete disintegration (residual strength) so that pre-peak properties (modulus, damage threshold, peak strength) and post-peak properties (brittleness, dilation angle, residual strength, fragmentation) can be estimated. The potential power of the method is that it allows for site-specific consideration of joint fabric, loading conditions and material property variations. This may be particularly useful for cases in which the joint fabric is highly anisotropic or where the problem is sensitive to post-peak properties (e.g. in block or panel cave mining, where the rock mass must be fragmented to a reasonable size without blasting).

The SRM technique first was applied to the analysis of the Northparkes Lift 2 block cave (Pierce et al., 2007), and used spherical samples so that the changes in stress orientation and magnitude that accompanied caving at Northparkes could be simulated during testing. In an attempt to achieve an REV, the SRM samples were constructed with a diameter equal to 55 times the mean joint spacing. Joint slip and new crack growth were tracked in the samples during testing under site-specific stress paths, and these showed good agreement with what could be inferred from analysis of mining-induced microseismicity measured in the mine (Reyes- 
Montes et al., 2007). The SRM tests were used to derive estimates of rock mass modulus, damage threshold, peak strength and brittleness for input to large-scale finite difference (continuum) models of the cave. The resulting cave simulations (employing SRM-derived properties) were able to simulate successfully the growth in seismogenic and yielded zones around the cave as inferred from in situ monitoring via geophones, time domain reflectometry (TDR) and open holes.

Since the first application at Northparkes Lift 2 Mine, the SRM methodology has been developed further to allow for standard testing (uniaxial, triaxial and direct tension) in each coordinate direction and at different scales. This allows for more general characterisation of rock mass properties, and can be used to quantify anisotropy and the effect of scale on rock mass properties. This new methodology is described in Mas Ivars et al. (2008a). Here, we focus on describing the results of more recent tests aimed at quantifying the effect of scale on rock mass strength for three rock mass units from the Palabora mine in South Africa: Carbonatite, Dolerite and Micaceous Pyroxenite.
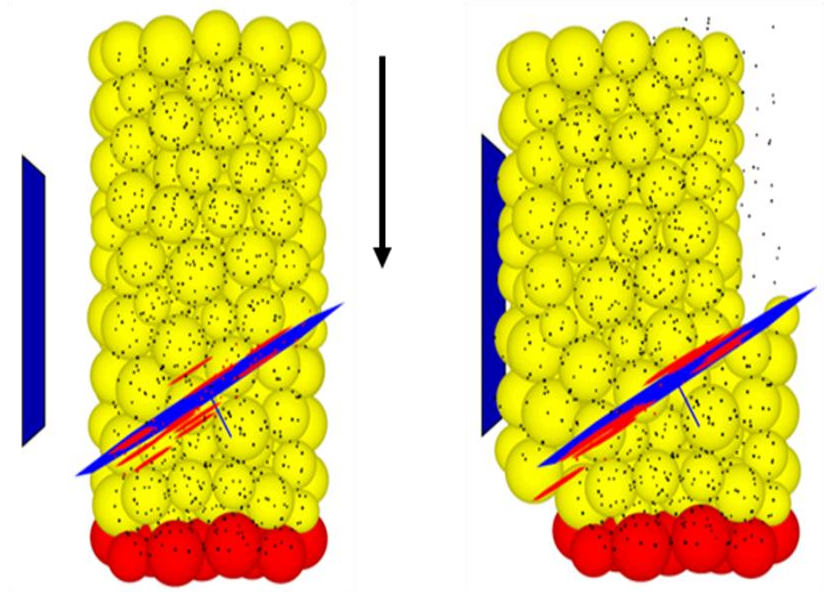

Figure 5 Illustration of the SJM. The sample consists of bonded spheres with an unbonded joint denoted by the inclined solid plane. The upper section slides on the plane under the action of gravity (lower spheres are fixed). Note that particles "pass through" each other in order to respect the given sliding direction. The vertical plane is a fixed wall; the inclined isolated planes are individual contact planes associated with the joint

\section{Scale effects observed in SRM samples}

\subsection{Sample creation and testing}

An SRM sample is created by embedding a DFN inside a large block of bonded particles in $P F C 3 D$. The three main inputs to DFN generation are the joint orientation, size distribution and density (as quantified by fracture frequency). These were derived from analysis of open joint data collected from pit wall mapping, underground mapping and core logging. The joints at Palabora are predominantly subvertical in orientation and exhibit two dominant strike directions (WNW and NNE). The joint spacing varies considerably: for example, Table 1 indicates the data range for the Carbonatite, as an example. It was difficult to estimate the joint size distribution at Palabora because, in most cases, the joint traces cut completely across the faces being mapped. In the absence of further information to constrain joint size (e.g. through measurement of trace lengths and terminations over multiple benches), it was necessary to make a significant assumption about the fracture size distribution; a power-law model with a length exponent equal to -4 ultimately was employed. Due to the large joint sizes present in such a DFN, a large generation volume equal to a cube of edge-length $100 \mathrm{~m}$ was employed for the Carbonatite and Micaceous Pyroxenite. A smaller cube of edgelength $50 \mathrm{~m}$ was used for the Dolerite, which had greater fracture frequency.

The microproperties controlling strength and stiffness of the bonded particle assembly (representing intact rock) were obtained via calibration to measured intact rock properties using the standard procedures outlined by Potyondy and Cundall (2004). The target intact rock properties (unconfined compressive strength (UCS), 
Young's modulus and Poisson's ratio) were established by scaling the properties obtained from standard uniaxial-compression tests on core samples to what might be expected for an average-sized rock block within each lithology, estimated from the mean joint spacing. The relation proposed by Hoek and Brown (1980) was used to justify scaling laboratory UCS by $80 \%$ to obtain rock-block strength. The target and calibrated values for UCS, Young's modulus and Poisson's ratio for the three rock types (Carbonatite, Dolerite and Micaceous Pyroxenite) are listed in Table 2. All calibrations were performed with PFC3D.

Table 1 Measured joint frequencies and assumed joint sizes for Carbonatite

\begin{tabular}{lcc}
\hline & Joint Frequency & Joint Diameter \\
\hline Mean & $0.77 \mathrm{~m}^{-1}(0.53-0.83)^{*}$ & $14.98 \mathrm{~m}$ \\
Min-max & $0.04^{-1}-3.64 \mathrm{~m}^{-1}$ & $10-354.7 \mathrm{~m}$ \\
\hline
\end{tabular}

* West Carbonatites 0.83, South Carbonatites 0.53

Table 2 Target (Lab.) and calibrated (Cal.) intact rock block properties for the three rock types

\begin{tabular}{lcccccc}
\hline & Carb. & Carb. & Dol. & Dol. & Mic. Pyrox. & Mic. Pyrox. \\
& Lab. & Cal. & Lab. & Cal. & Lab. & Cal. \\
\hline Mean measured UCS (MPa) & 139 & & 320 & & 90 & \\
Estimated rock-block strength (MPa) & 111.2 & 112.7 & 256 & 257.5 & 72 & 72.7 \\
Young's modulus, E (GPa) & 58 & 58.4 & 90 & 92.5 & 72 & 72.5 \\
Poisson's ratio, $v$ & 0.33 & 0.33 & 0.3 & 0.3 & 0.35 & 0.35 \\
\hline
\end{tabular}

Once the microproperties for the bonded particle assembly were established, cubic specimens of $80 \mathrm{~m}$ (Carbonatite and Micaceous Pyroxenite) or $40 \mathrm{~m}$ (Dolerite) side length were produced using a rapid generation procedure that replicates a pre-compacted brick derived from a periodic assembly. The DFN was then embedded inside the intact rock cube, with each joint segment being represented by the SJM (Mas Ivars et al., 2008b). Joint properties were estimated from the roughness and hardness of joints measured during mapping, and are listed in Table 3. Dilation in all cases is assumed to be zero.

Table 3 Estimated joint properties

\begin{tabular}{lccc}
\hline & Carbonatite & Dolerite & Micaceous Pyroxenite \\
\hline Normal stiffness $(\mathrm{GPa} / \mathrm{m})$ & 150 & 250 & 150 \\
Shear stiffness $(\mathrm{GPa} / \mathrm{m})$ & 20 & 30 & 20 \\
Friction angle (degrees) & 30 & 26 & 34 \\
Cohesion $(\mathrm{MPa})$ & 0 & 0 & 0 \\
\hline
\end{tabular}

The next step involved carving three $80 \mathrm{~m}$ x $40 \mathrm{~m}$ x $40 \mathrm{~m}$ parallelepiped samples from the centre of the generic $80 \mathrm{~m}$ cube in the three axial directions (half this size for the Dolerite samples). After that, each of these three large samples was divided into eight medium-sized samples. Finally, one of the medium-sized samples in each of the axial directions was subdivided into eight small parallelepiped samples. In this manner, a total of 51 specimens of 2:1 aspect ratio were generated for each lithology: 24 small-sized specimens ( 8 in each axial direction); 24 medium-sized specimens (8 in each axial direction); and 3 largesized samples ( 1 in each axial direction). The 51 specimens then were submitted to numerical simulations of direct tension, UCS and triaxial compression (5 MPa confinement). The process of progressively subdividing specimens is illustrated in Figure 6. The distinct levels of shading correspond to contiguous blocks, within which any particles may be reached from any other via one or more intact bonds. Between such blocks, there are unbonded contacts associated with joint segments. During loading, samples become more fragmented as 
bonds break. Although a block is identified with a uniform shading, it may contain many 'dead-end' fractures that may extend during loading.

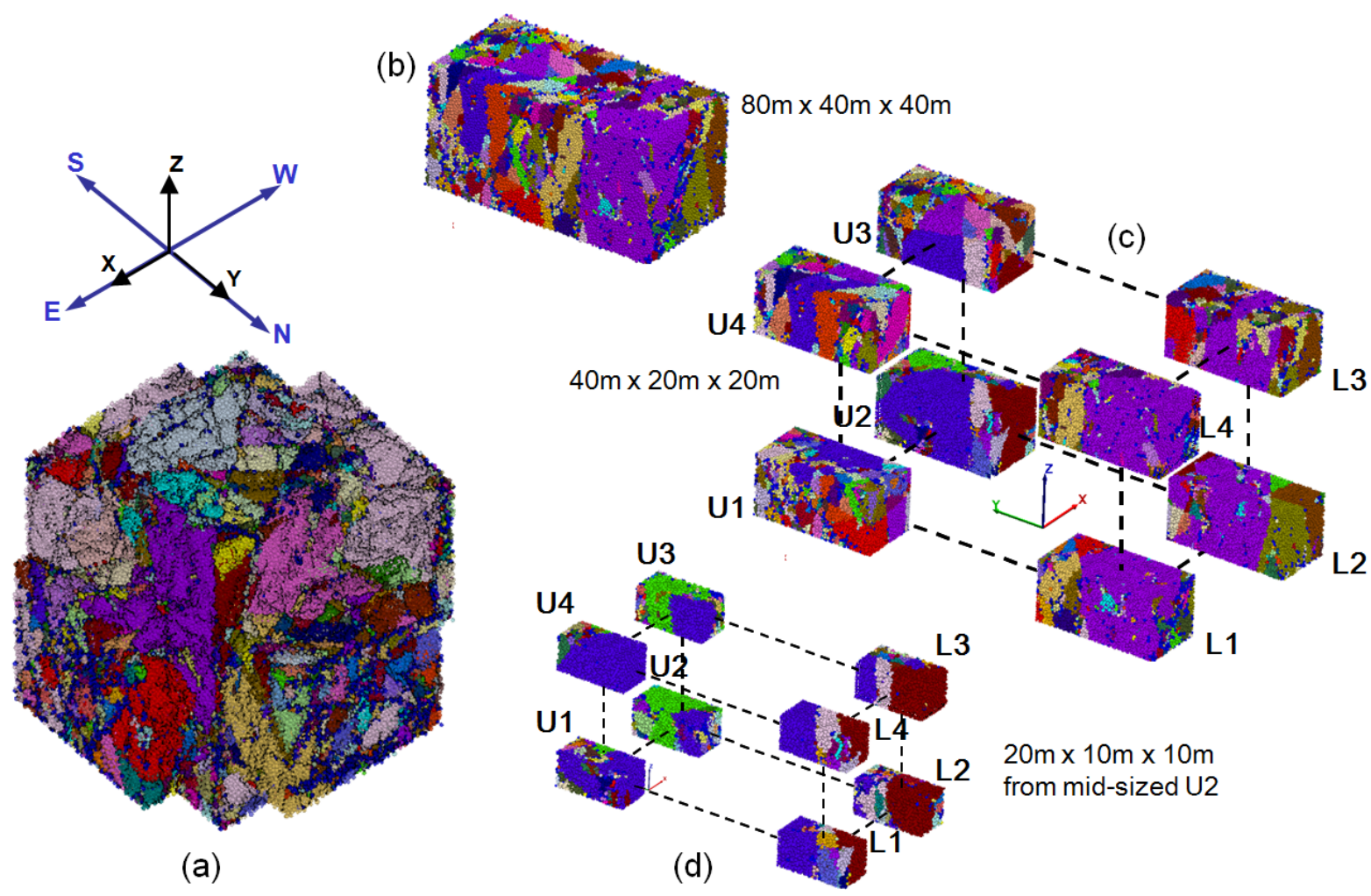

Figure 6 Progressively smaller samples extracted from large master sample. Distinct levels of shading show contiguous blocks that are separated by joint segments

\subsection{Results}

Figures 7, 8 and 9 show the unconfined compressive strength measured for synthetic samples of Carbonatite, Dolerite and Micaceous Pyroxenite samples, respectively, versus sample widths. Table 4 lists standard deviations for two sample sizes for each of the three rock types. In general, the variation decreases with increasing size. The variation in strength is illustrated graphically in Figure 10, in which each group of bars corresponds to a single sample $(10 \times 20 \mathrm{~m})$ of a single rock type (Carbonatite). In each group, the anisotropy is reflected by the relative heights of the three bars corresponding to the $\mathrm{X}-$, Y- and Z-directions of testing. Similar results for Young's modulus are shown in Figure 11. There is a strong correlation between UCS and Young's modulus.

\subsection{Discussion}

A strong size effect is evident for the three SRMs, although each rock type exhibits its own particular shape of strength-size curve (e.g. contrast Figure 9 with Figures 7 and 8; clearly, the Micaceous Pyroxenite results have not yet become asymptotic). The main cause for the size effect seems to be that considerable intact-rock (rock bridge) failure is necessary for rock mass failure to occur in small volumes of the material, while slip and opening can accommodate failure in larger samples because of the increased availability of suitable joint planes. Another way of looking at the mechanism is in terms of average rock-block size in relation to sample size, which was expressed in Figure 3 as a way to non-dimensionalise the GSI interpretation of Cai et al. (2004).

There is also a strong size effect in the magnitude of strength fluctuations, whereby a collection of small samples exhibits a wide variability in strength, compared to a collection containing a similar number of large samples. The strength fluctuations correspond closely to modulus fluctuations.

Several other results, obtained from the same series of tests, cannot be included here because of length constraints. First, it is noted that brittleness (post-peak softening rate) decreases in general with increasing 
size of sample, as more failure is accommodated by sliding on existing joint planes. Second, the size effect noted for UCS tests also is observed in triaxial tests. Finally, results have been obtained for the changes in fragmentation (size distribution) that occur during failure for different sample sizes.

By necessity, the DFNs used in preparing numerical samples contain populations of joint segments that are truncated at both ends of their size range. The effect of such truncation is unknown, but its impact on the observed size effect will be quantified in future work.

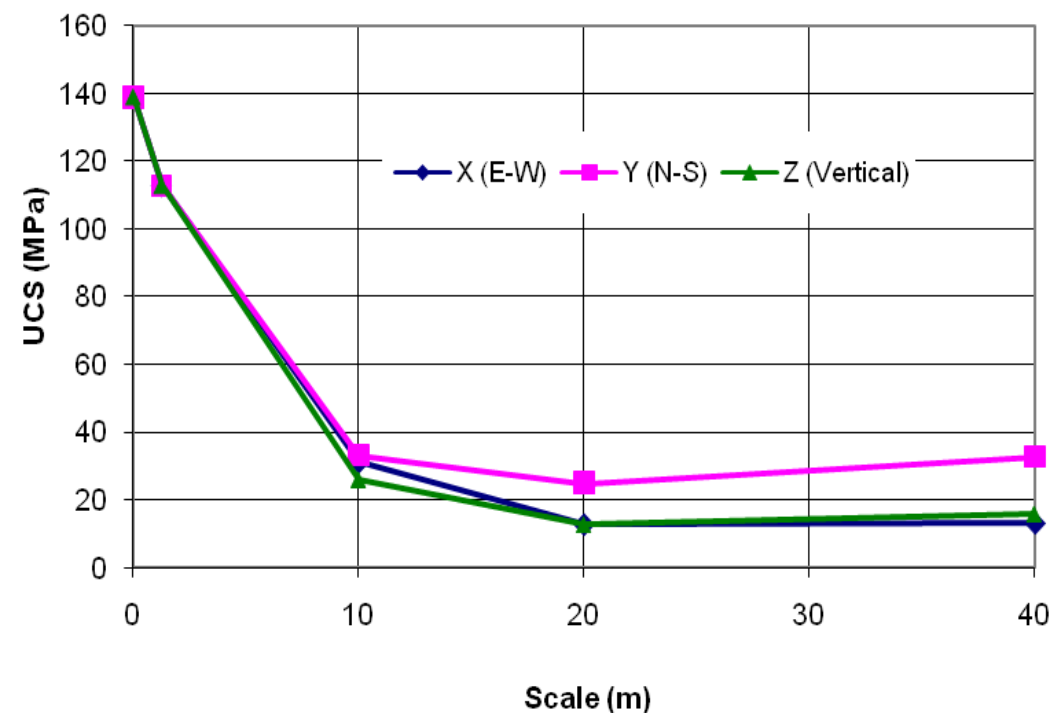

Figure 7 Numerically obtained values of unconfined compressive strength of Carbonatite versus sample thickness for three orientations of the applied axial stress. The left-most point corresponds to intact rock; the next point represents the degraded strength of the mean block size (see Table 2)

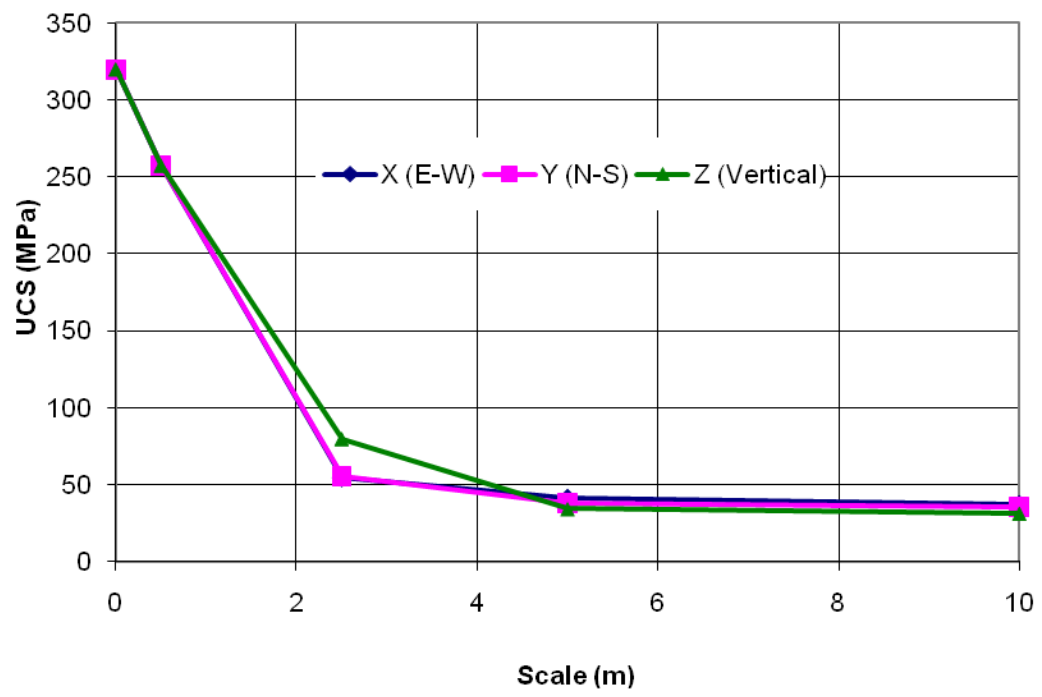

Figure 8 Numerically obtained values of unconfined compressive strength of Dolerite versus sample thickness for three orientations of the applied axial stress. The left-most point corresponds to intact rock, while the next point represents the degraded strength of the mean block size 


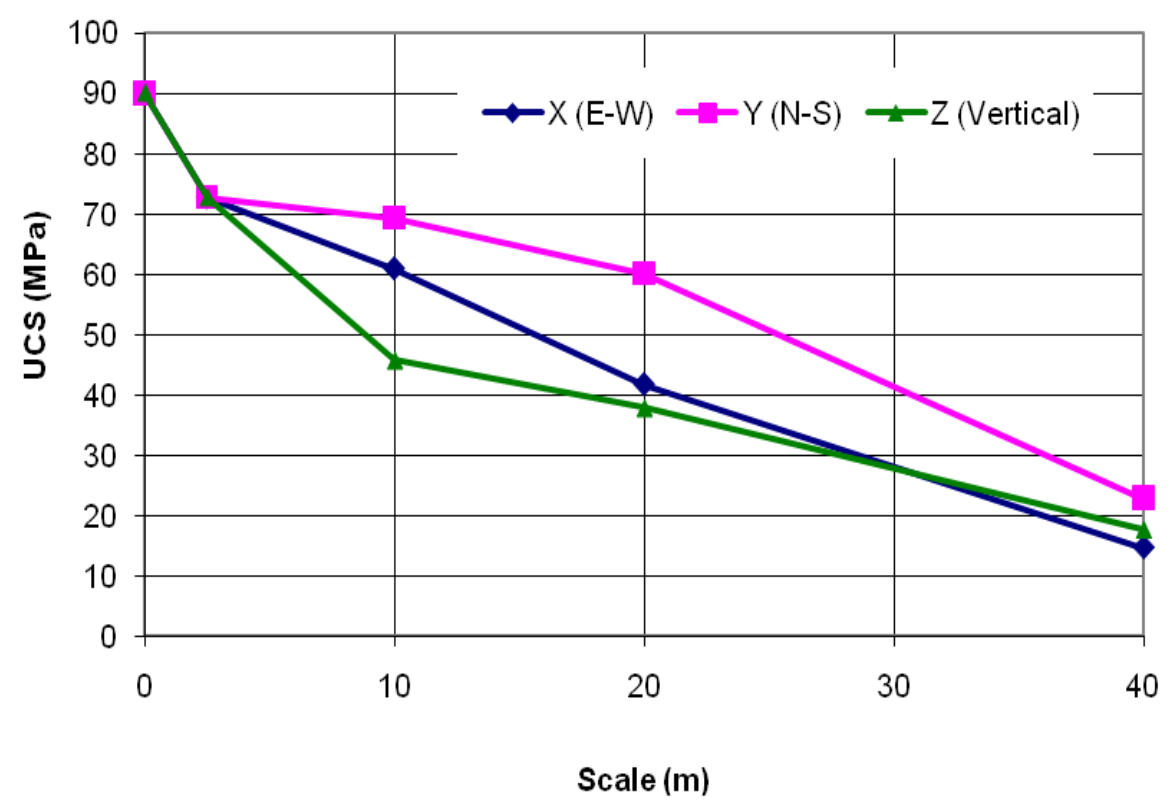

Figure 9 Numerically obtained values of unconfined compressive strength of Micaceous Pyroxenite versus sample thickness for three orientations of the applied axial stress. The left-most point corresponds to intact rock; the next point represents the degraded strength of the mean block size

Table 4 Measured standard deviations in UCS for all sub-samples (8 tests for each case)

\begin{tabular}{lcc}
\hline Rock Type & Sample Size & Standard Deviation \\
\hline Carbonatite & $10 \times 20 \mathrm{~m}$ & $18.72 \mathrm{MPa}$ \\
Carbonatite & $20 \times 40 \mathrm{~m}$ & $6.99 \mathrm{MPa}$ \\
Dolerite & $2.5 \times 5 \mathrm{~m}$ & $46.5 \mathrm{MPa}$ \\
Dolerite & $5 \times 10 \mathrm{~m}$ & $26.2 \mathrm{MPa}$ \\
Micaceous pyroxenite & $10 \times 20 \mathrm{~m}$ & $16.1 \mathrm{MPa}$ \\
Micaceous pyroxenite & $20 \times 40 \mathrm{~m}$ & $9.5 \mathrm{MPa}$ \\
\hline
\end{tabular}




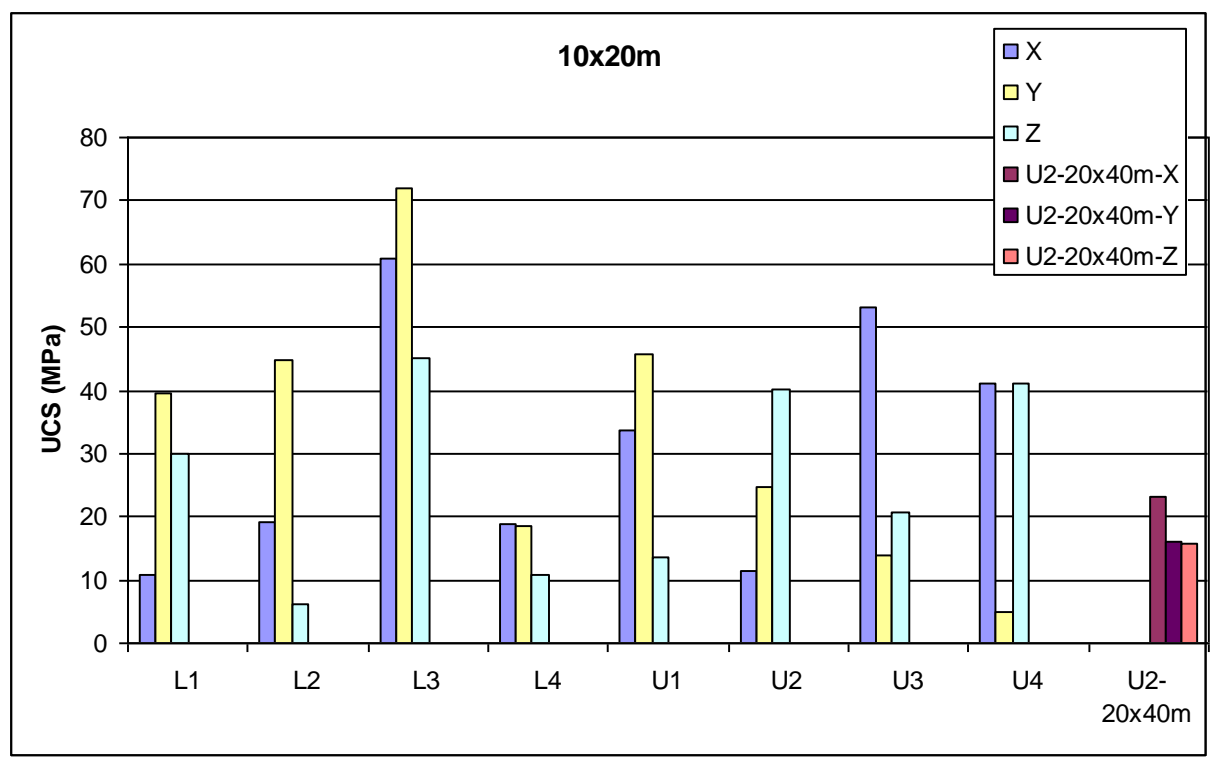

Figure 10 UCS values for each of eight $10 \times 20 \mathrm{~m}$ Carbonatite samples (the three bars in each sample group correspond to $\mathrm{X}$-, $\mathrm{Y}$ - and $\mathrm{Z}$-axial directions, respectively). The bars at far right correspond to the 'parent' sample of $20 \times 40 \mathrm{~m}$

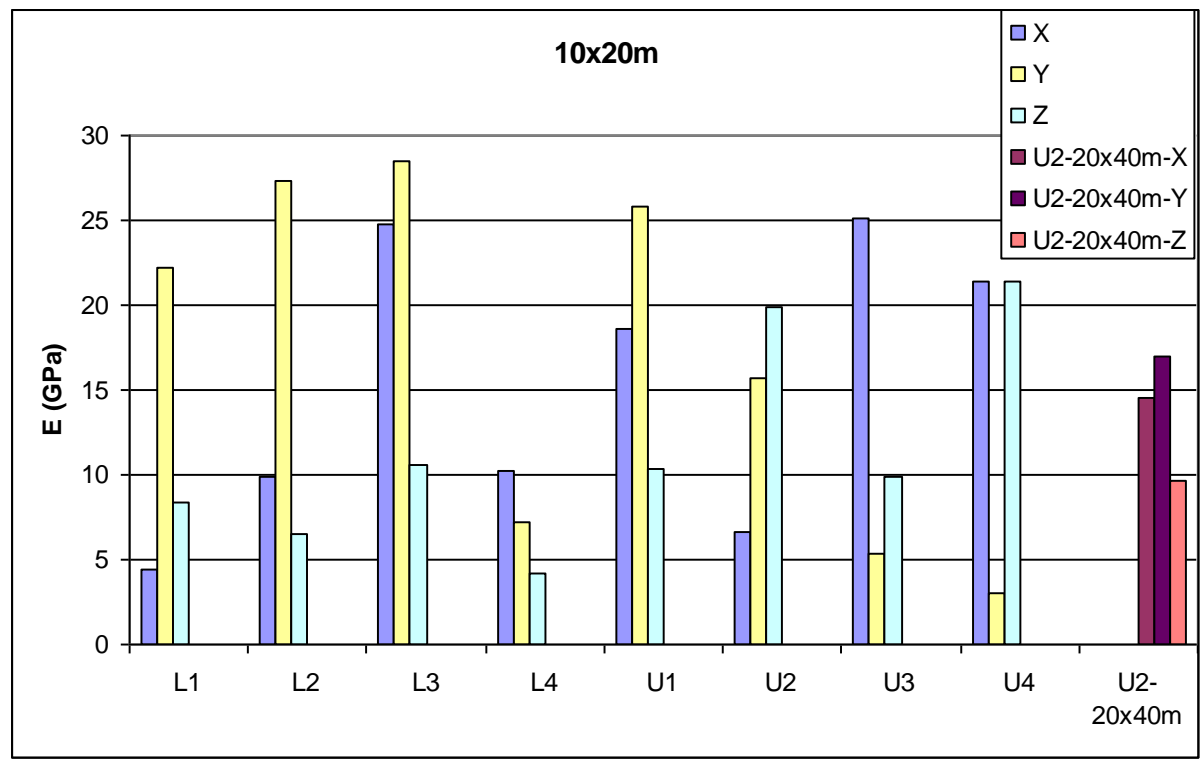

Figure 11 Young's modulus values for each of eight $10 \times 20 \mathrm{~m}$ Carbonatite samples (the three bars in each sample group correspond to $\mathrm{X}$-, Y- and Z-axial directions, respectively). The bars at far right correspond to the 'parent' sample of $20 \times 40 \mathrm{~m}$

\section{Conclusions}

The behaviour of a rock mass may be synthesised numerically by the SRM approach in which a DFN is superimposed upon a bonded-particle assembly representing the intact rock. The SRM incorporates all available geological and mechanical data, and captures the complex mechanisms that must occur during failure of a rock mass, including intact-rock fracture, and slip and opening on joints. In particular, 3D tests on SRM samples of varying size reveal a strong size effect on strength. Such a size effect has been estimated empirically, but we now can quantify it, based on measurable properties and geometry of the components of the rock mass. The results of SRM element tests may be compared to empirically based GSI charts. We also 
observe significant deviations that arise from multiple realisations, each of which conforms to the same DFN statistics.

Two main conclusions may be made. First, it is now possible to derive, by numerical testing of SRMs, a prediction of the strength of the rock mass comprising an engineering structure of given size. We note that large structures (e.g. block-cave mines and large slopes) will require the use of a lower strength in design than smaller structures, such as tunnels, given the same geological environment. The second conclusion is that large variations in strength are to be expected, manifested as spatial fluctuations. The magnitudes of such fluctuations also may be quantified by SRM testing. There is evidence (Jefferies et al., 2008) that the factor of safety of a rock structure may be reduced significantly when spatial fluctuations in strength exist.

We believe that empirical estimates of rock mass strength, such as GSI, should be supplemented routinely by numerical estimates using the SRM approach when designing important engineering sites.

\section{Acknowledgements}

We acknowledge the support of the MMT (Mass Mining Technology) project, administered by SMI (Sustainable Minerals Institute) in Brisbane and the LOP (Large Open Pit) project administered by CSIRO in Brisbane, and in particular sponsors Rio Tinto, Northparkes mine and Palabora mine. The valuable contributions of Caroline Darcel (Itasca Consultants S.A.S., France), David Potyondy and David DeGagné (Itasca Consulting Group, Inc., Minneapolis, USA) to the work reported here are gratefully acknowledged.

\section{References}

Bažant, Z.P. and Chen, E-P. (1997) Scaling of structural failure. Applied Mechanics Review, 50(10).

Bieniawski, Z.T. and Van Heerden, W.L. (1975) The significance of in situ tests on large rock specimens. International Journal of Rock Mechanics and Mining Sciences and Geomechanics Abstracts, 12, pp. 101-113.

Brady, B.H.G. and Brown, E.T. (2004) Rock mechanics for underground mining, 3rd Edition. Kluwer Academic, Dordrecht.

Cai, M., Kaiser, P.K., Uno, H., Tasaka, Y. and Minami, M. (2004) Estimation of rock mass strength and deformation modulus of jointed hard rock masses using the GSI System. International Journal of Rock Mechanics and Mining Sciences, 41(1), pp. 3-19.

Cunha, A.P. (editor) (1990) Scale effects in rock mechanics. Proceedings First International Workshop on Scale Effects in Rock Masses, Loen, Norway, June, Balkema, Rotterdam, pp. 3-31.

Goodman, R.E. (1980) Introduction to rock mechanics. Wiley and Sons, New York.

Hoek, E. and Brown, E.T. (1980) Underground Excavations in Rock. London, Institution of Mining and Metallurgy.

Hoek, E. and Brown, E.T. (1997) Practical estimates of rock mass strength, International Journal of Rock Mechanics and Mining Sciences, 34(8), pp. 1165-1186.

ICSAS (Itasca Consultants S.A.S.) (2006) 3FLO, version 2.2. ICSAS, Lyon.

Itasca Consulting Group Inc. (Itasca) (2004a) UDEC (Universal Distinct Element Code), version 4.0, Itasca, Minneapolis.

Itasca Consulting Group Inc. (Itasca) (2004b) 3DEC (3-Dimensinal Distinct Element Code), version 3.0, Itasca, Minneapolis.

Itasca Consulting Group Inc. (Itasca) (2007) PFC3D (Particle Flow Code in 3 Dimensions), version 4.0, pre-release, Itasca, Minneapolis.

Jefferies, M., Lorig, L. and Alvarez, C. (2008) Influence of rock-strength spatial variability on slope stability. Continuum and Distinct Element Numerical Modeling in Geo-Engineering, Proceedings First International FLAC/DEM Symposium on Numerical Modeling, R. Hart, C. Detournay and P. Cundall (editors) 24-26 August. Minneapolis, Itasca Consulting Group (in press).

Kim, B.H., Cai, M., Kaiser, P.K. and Yang, H.S. (2007) Estimation of Block Sizes for Rock Masses with Non-persistent Joints. Rock Mechanics and Rock Engineering, 40(2), pp. 169-192.

Mas Ivars, D., Pierce, M., DeGagné, D. and Darcel, C. (2008a) Anisotropy and scale dependency in jointed rock-mass strength-A synthetic rock mass study. Continuum and Distinct Element Numerical Modeling in GeoEngineering, Proceeding First International FLAC/DEM Symposium on Numerical Modeling, R. Hart, C. Detournay and P. Cundall (editors) 24-26 August, Minneapolis, Itasca Consulting Group (in press).

Mas Ivars, D., Potyondy, D.O., Pierce, M. and Cundall, P.A. (2008b) The smooth-joint contact model. Proceedings 8th World Congress on Computational Mechanics/5th European Congress on Computational Methods in Applied Sciences and Engineering, in press. 
Mostyn, G. and Douglas, K. (2000) The shear strength of intact rock and rock masses. GeoEng 2000: An International Conference on Geotechnical and Geological Engineering (Melbourne, Australia), Vol. 1, Technomic Publishing, Lancaster, Pennsylvania, pp. 1398-1421.

Park, E-S., Martin, C.D. and Christiansson, R. (2004) Simulation of the mechanical behavior of discontinuous rock masses using a bonded-particle model. Gulf rocks 2004: Rock Mechanics Across Borders and Disciplines, D. Yale, S. Willson and A. Abou-Sayed (editors), Paper no. ARMA/NARMS 04-480.

Pierce, M., Cundall, P., Potyondy, D. and Mas Ivars, D. (2007) A synthetic rock mass model for jointed rock. Rock mechanics: Meeting society's challenges and demands, Vol. 1: Fundamentals, new technologies and new ideas, E. Eberhardt, D. Stead and T. Morrison (editors), Taylor and Francis, London, pp. 341-349.

Potyondy, D.O. and Cundall, P.A. (2004) A bonded-particle model for rock, International Journal of Rock Mechanics and Mining Sciences, 41, pp. 1329-1364.

Reyes-Montes, J., Pettitt, W. and Young, R.P. (2007) Validation of a Synthetic Rock Mass model using excavation induced microseismicity, Rock mechanics: Meeting society's challenges and demands, E. Eberhardt, D. Stead and T. Morrison (editors), Taylor and Francis Group, London, Vol. 1, pp. 365-369.

Rocha, M. (1974) Present possibilities of studying foundations of concrete dams, Advances in rock mechanics, National Academy of Sciences, Washington, D.C.

Schultz, R.A. (1996) Relative scale and the strength and deformability of rock masses. Journal of Structural Geology, 18(9), pp. 1139-1149.

Wang, C., Tannant, D.D. and Lilly, P.A. (2003) Numerical analysis of the stability of heavily jointed rock slopes using PFC2D, International Journal of Rock Mechanics and Mining Sciences, 40, pp. 415-424.

Weibull, W. (1939) A statistical theory of the strength of materials. Ingeniors Vetenskaps Akademien, Handlingar, Vol. 151-3, pp. 45-55. 
